\title{
Water Balance Model of Lake Malawi and its Sensitivity to Climate Change
}

\author{
Patsani G Kumambala*,1 and Alan Ervine ${ }^{2}$ \\ ${ }^{I}$ Department of Civil Engineering, University of Glasgow, Glasgow, Scotland G12 8LT, UK \\ ${ }^{2}$ Department of Water Engineering, University of Glasgow, UK
}

\begin{abstract}
Sustainable water resources development of Malawi needs a thorough assessment of the impact of climate change on the future water levels of Lake Malawi because Lake Malawi together with its outflowing Shire river water system is Malawi's most important water resource for hydropower generation, water supply for industrial and domestic use in the city of Blantyre and its surrounding urban areas together with irrigation water in the Lower Shire Valley (LSV). Any changes in the hydrological or ecological behaviour of the lake will have far reaching consequences on the economy of Malawi. This paper reviews the current literature on the water balance studies of Lake Malawi and introduces climate change modelling into the water balance model to assess the likely future behaviour of the lake.
\end{abstract}

Keywords: Malawi, water balance, climate change, hydrology.

\section{BACKGROUND}

Lake Malawi is the third largest Lake in Africa after Lake Victoria and Tanganyika [1]. Lake Malawi drains a catchment area of $126,500 \mathrm{~km}^{2}$ including the lake. The lake surface area is $28,800 \mathrm{~km}^{2}$ and the lake is $579 \mathrm{~km}$ long, $25-80$ $\mathrm{km}$ wide with a maximum depth of $700-785 \mathrm{~m}$ and mean depth of $292 \mathrm{~m}[1,2]$. The land catchment area of Lake Malawi is $97,740 \mathrm{~km}^{2}$ and it covers parts of Malawi, Mozambique and Tanzania as shown in Fig. (1). Malawi contributes the lion share of the land catchment of $66,810 \mathrm{~km}^{2}(68.35 \%)$, seconded by Tanzania with $25,470 \mathrm{~km}^{2}(26 \%)$ and Mozambique $5.460 \mathrm{~km}^{2}(5.58 \%)$ [2].

Rainfall over Lake Malawi and its catchment area closely correlate with relief, such that highlands and escarpment areas experience greater precipitation than the low lying and rain shadow areas [3]. Nyika and Vipya plateau in the north are the prominent highlands in Lake Malawi catchment area with high rainfalls in the excess of $1800 \mathrm{~mm}$ annual rainfall while the low lying areas such as the plateau regions to the west receive low rainfall in the range of 700 to $800 \mathrm{~mm}$ annual rainfall [3].

Lake Malawi and the Shire river system play a major role in Malawi's economic sector. Lake Malawi is the main source of water for all the country's hydropower stations located along the Shire river with a total installation capacity of 280 MW. Further South, the Shire is the main source of water for the country's largest sugar plantation at Nchalo and other irrigation schemes in the Lower Shire Valley (LSV) and supplies water to the city of Blantyre (Fig. 1). The lake also serves as a medium for water transportation which is

*Address correspondence to this author at the Department of Civil Engineering, University of Glasgow, Glasgow, Scotland G12 8LT, UK; Tel: + 44141330 5210; Fax: + 44141330 4557;

E-mail: patsanikumambala@yahoo.co.uk conducted by government owned Malawi Lake Services (MLS). It is feared that the low lake level which was the case between 1915 and 1935 when there was no outflow from the lake into the Shire river, would seriously affect downstream users along the Shire as well as water transport [4]. The lowest lake level of $469 \mathrm{~m}$ above sea level was experienced in $1915[4,5]$.

Lake Malawi is also recognised as a world heritage site as it is home to an estimated $500-1000$ fish species, exceeding any other lake in the world [6]. It is thought that the Cichlidae species which make up $90 \%$ of the fish species found in the lake are indigenous to the lake [7].

Despite the enormous benefits, the lake sometimes causes problems especially to people living along the lake shore. The problem comes especially due to abnormally high water levels during the rainy season [2]. In the late 1970's the water level of the lake rose sharply and reached a maximum level of $477 \mathrm{~m}$ in 1980 . This resulted in floods along the lake shore, where fertile agricultural land was submerged and towns and villages were destroyed [2]. Rising levels also affects the downstream communities of the Lower Shire Valley as the high levels require maximum opening of the Liwonde barrage to release enough water from the lake. The Liwonde barrage is shown in Fig. (1) acts to control outflows from Lake Malawi. Large outflows from the lake combined with high flows from Ruo river which flows from Mulanje mountains have always been a major cause of floods in the Lower Shire Valley.

In recent years flooding along the Lower Shire valley (LSV) has been a perennial phenomenon and in 2008 during the rainy season over 32,000 people were affected by floods in the LSV [8].

The outlined benefits and strategic importance of Lake Malawi calls for sustainable management of its unique ecosystem. One of the major challenges facing the sustainability of water resources is climate change. Climate change has 


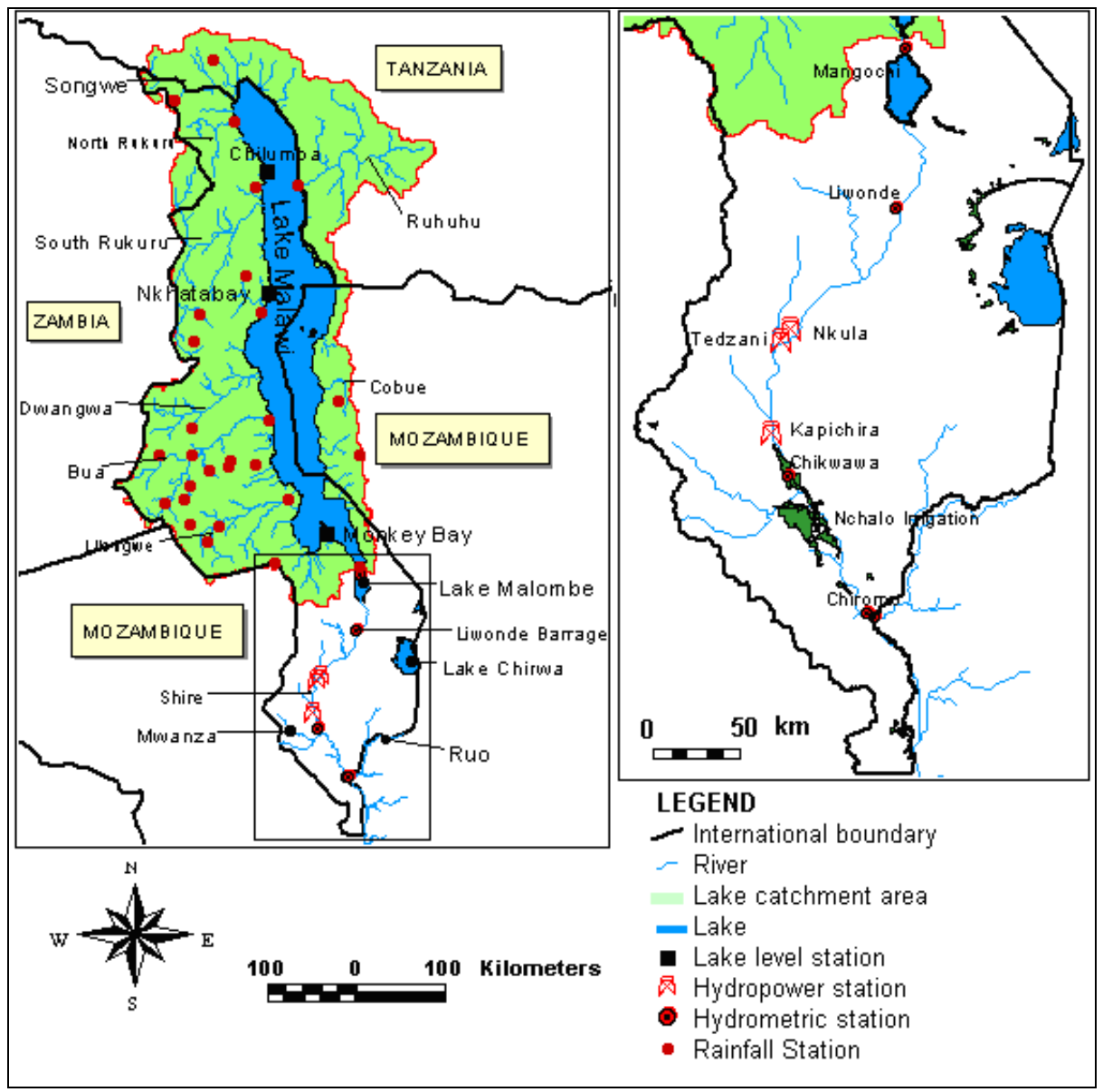

Fig. (1). Lake Malawi and Shire river system showing the major water resources development in the Lower Shire Valley.

emerged to be a threat to the sustainability of the water resources because it is a long term process which has resulted in extreme weather condition in many different parts of the world [9]. In Malawi the observed climate changes are evidenced by the changes in the rainfall season, pattern and temperature, and changes in the frequency of droughts and floods [10] as well as significant variations in Lake Malawi and river levels $[5,11]$. It is therefore necessary to combine studies of water balance model with studies of climate change effects on the water resources if sustainability of water resources is to be maintained [3].

\section{REVIEW OF WATER BALANCE MODELS OF LAKE MALAWI}

A water balance model is a mathematical expression used to describe the flow of water in and out of a hydrological system such as drainage basin or lake [12]. Water balance model has wider application in water resources management by predicting where there may be shortages or surplus water. In the last 3 decades a number of studies have been conducted regarding the water balance of Lake Malawi and its levels. It is therefore the interest of this paper to review the current models with an aim to introduce climate change scenario testing into the existing models. This will provide insights into the future behaviour of the lake.

Lake Malawi has been a subject of a number of studies since the Halcrow study 1954 (cited by Kidd 1983 [4]). In 1983, Kidd conducted a thorough evaluation of the water resources of Lake Malawi and Shire river system based on
26 years of the available data by that time. The outflow was based on flows at the Liwonde barrage. The model was designed to simulate historical mean monthly lake levels. However no firm prediction of the future behaviour of the lake was undertaken due to lack of modelling tools to predict future rainfall behaviour. Further studies on the water balance of the lake by Neuland (1984) revealed a gain in lake level of $0.11 \mathrm{~m}$ based on 26 years of data from 1954 to 1976. Neuland's approach was similar to that of Kidd (1983). Frequency analysis of the future behaviour of the lake by Neuland (1984) has revealed that there is little risk of the lake level exceeding $477.8 \mathrm{~m}$ above mean sea level. Using the most recent observed climate parameters of the lake, the predicted level by Neuland (1984) remains below 477 m. Probability analysis of future projected levels of the lake have shown a tendency to fall approaching gradually equilibrium of $475 \mathrm{~m}$ amsl [2]. Similar studies on water balance by Drayton [13] in 1984 revealed a net positive change in storage between 1953 and 1974. Drayton's (1984) model was similar to Kidd's (1983) and Neuland's (1984) model, and was aimed at predicting annual maximum monthly water levels. Table $\mathbf{1}$ is a summary of the net change in storage based on previous studies.

The most recent work on the water balance of Lake Malawi is the study done by Calder et al. (1995). Calder et al. (1995) studied the impact of land use change on the water levels of the lake using a water balance model. The model simulation for the period 1954 to 1994 was equally good and more consistent with decrease in Lake Malawi catchment 
Table 1. Net Water Storage of Lake Malawi Based on Previous Studies

\begin{tabular}{|c|c|c|c|}
\hline Researcher & Kidd (1983) [4] & Neuland (1984) [2] & Drayton (1984) [13] \\
\hline \hline Data period & $1954-1979$ & $1954-1979$ & $1953-1974$ \\
\hline Rainfall over the lake (mm) & 1414 & 693 & 693 \\
\hline Inflow into the lake (mm) & 1000 & 1605 & 1610 \\
\hline Lake Evaporation (mm) & 1872 & 404 & 334 \\
\hline Outflow from the lake (mm) & 418 & +58 & +59 \\
\hline Change in storage (mm) & +112 & & \\
\hline
\end{tabular}

forest cover of $13 \%$ over the 1967 to 1990 period. Calder et al. (1995) and Neuland (1984) have recognised that increases in rainfall will lead to abnormally high lake levels, accelerated by the change in runoff characteristics in the catchment due to reduced forest cover. All the previous studies on the water balance model were based on the net balance between inflow from lake catchment $Q_{\text {in }}$, rainfall $R_{L}$ and evaporation Evap $_{L}$ over the lake and Shire river outflow $Q_{\text {out }}$ in estimating the change in lake water storage $\Delta S$ as shown in and equation 1 .

$$
\Delta S=R_{L}+Q_{\text {in }}-\text { Evap }_{L}-Q_{\text {out }}
$$

From the review on the water balance model, it has been noted that climate change impact has until now not been considered in predicting future behaviour of the lake. Further to that outflows from the lake have always been based on flows at Liwonde barrage (Liwonde hydrometric station shown in Fig. 1) which are always affected by the operation of the barrage, direct rainfall and evaporation within the catchment area between the lake outlet and the barrage, variation in the storage of Lake Malombe. In this investigation, downscaled climate data will be used in the water balance model based on current flows at main lake outlet (Mangochi) to assess the future behaviour of the lake. This is motivated by new threats of low lake levels in recent years as well as high spatial variability in rainfall over Lake Malawi catchment area. In addition, a new water balance model would be beneficial due to the long time period since the previous studies were conducted. Climate data downscaled from GCM using Statistical Downscaling Model described by Wilby and Dwason (2007) will be used to assess future behaviour of the lake as opposed to probability analysis which has always been used in the previous models in predicting future water levels of Lake Malawi.

\section{COMPONENTS OF WATER BALANCE MODEL OF LAKE MALAWI}

The water balance which governs the water level behaviour of Lake Malawi is a combination of runoff from rivers flowing into the lake, measured outflow from the lake, evaporation from the lake surface and rainfall on the lake as shown in Fig. (2) [2, 5]. Groundwater inflow and outflow has always been ignored in previous studies because of lack of piezometric data around the lake quantifying groundwater flow around the lake. Equation 1 is a simplification of the water balance of an open lake normally given by the following differential equation [14].

$$
\begin{aligned}
& \frac{d L}{d t}=R_{L}(t)-\operatorname{Evap}_{L}(t)+Q_{\text {bala }}+\varepsilon(t) \\
& Q_{\text {bala }}=\left(\frac{Q_{\text {in }}(t)-Q_{\text {out }}(t)+G_{\text {net }}(t)}{A_{L}(h)}\right)
\end{aligned}
$$

where $L$ is the water level in the lake, $G_{n e t}$ is the net groundwater flux, $A_{L}$ is the surface area of the lake, $Q_{\text {bala }}$ is net runoff and the other parameters have been described in equation 1 . The final term $\varepsilon$, represents uncertainties in the water balance arising from errors in the data and other terms such as minor abstraction or inflow from ungauged catchments.

\subsection{Inflow into the Lake $Q_{i n}$}

Runoff inflow into Lake Malawi is a combination of the runoff records from all the major catchments in Malawi, Tanzania and Mozambique shown in Fig. (1). Daily runoff data from Lake Malawi catchments was obtained from the Ministry of Irrigation and Water, Department of Hydrology in Lilongwe. This covered all inflows from Malawi catchment as well as Tanzania catchment. However data from Mozambique is still not available. Inflow data from Mozambique was estimated by extrapolation method described by Calder et al. (1995) [5]. Despite Malawi contributing the lion share of the land catchment, Tanzania contributes the majority of the runoff inflow into Lake Malawi as shown Fig. (3).

\subsection{Outflow from the Lake $Q_{\text {out }}$}

Outflows records from the lake are now available at Mangochi station from 1971 up to 2006. The relationship between mean monthly water levels and lake outflows at the

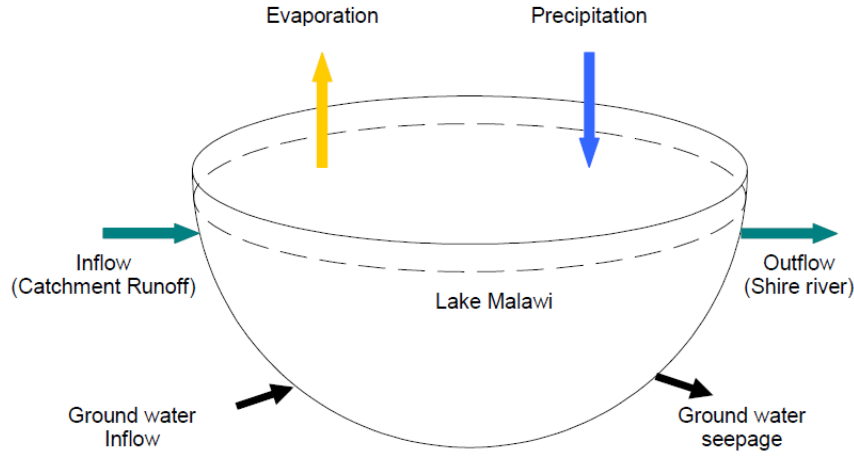

Fig. (2). Lake Malawi Water Balance Model Components. 


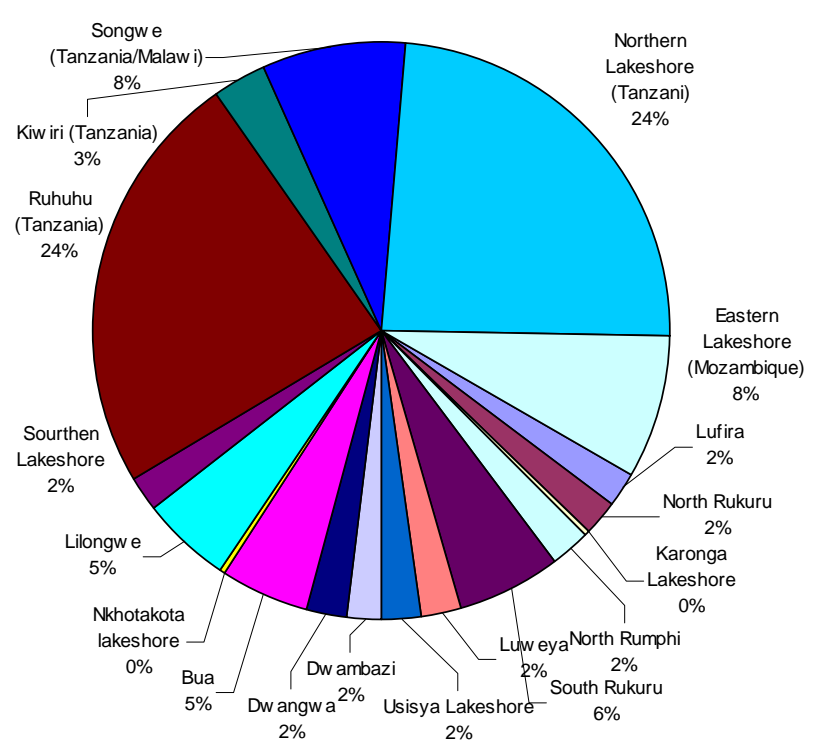

Fig. (3). Lake Malawi inflow contribution from different catchments.

Mangochi station is given in Fig. (4) and equation 5. There is a good correlation between the water level and the lake outflows at Mangochi ST1 station with Nash-Sutcliffe model efficiency $R^{2}=0.97$. The relationship between lake outflows and water levels for naturally unregulated lakes can be expressed by equation $4[14,15]$.

$Q_{\text {out }}=a\left(L_{\text {eff }}\right)^{b}$

$Q_{\text {out }}=30.285(L-470.8)^{1.9145}$

where $L_{\text {eff }}$ is the effective level of water responsible for outflow from the lake, and $a$ and $b$ are constants. The constant $b$ varies between 0 and 3 in many natural lakes. The $b$ value is always equal to 1 when there is a linear relationship between effective head and lake outflows while a lake with constant outflow will have a $b$ value of 0.00 .

A datum value of $470.8 \mathrm{~m}$ amsl in equation 5 was selected by optimising the best fit of the relationship of lake outflows vs. lake levels in Fig. (4). The $b$ value in equation 5 indicates that a small change in lake level would have a significant effect on the lake outflow. This shows that a small change in net inflow into the lake would result in a small change in lake level as well as lake surface area but a significant change in the lake outflow.

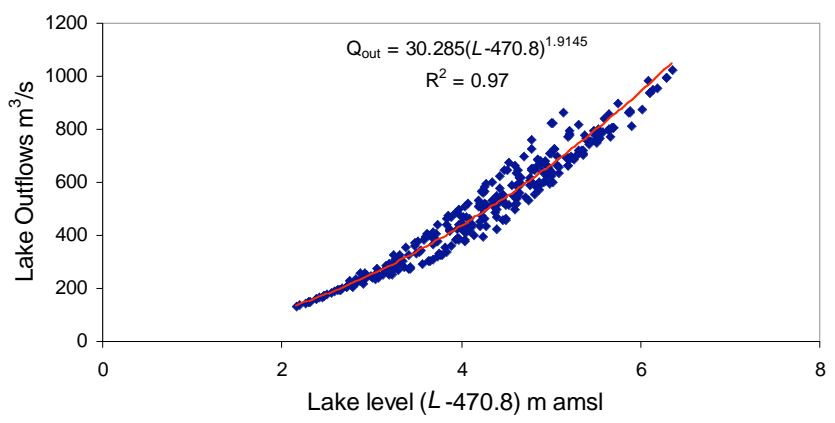

Fig. (4). Correlation of Lake Malawi water levels and outflows at Mangochi station.
Simulated outflows from the lake based on equation 5 were compared with observed flows at Mangochi station as shown in Fig. (5). The results show a good agreement between observed and estimated flows in the calibration period of 1971 to 1990 with a Nash-Sutcliffe $R^{2}=0.86$. The disagreement in the simulated and observed flows in the year 1988 and 1989 could be attributed to recording error in the lake level data or out flow data. The calibrated equation 5 was verified against observed lake outflows for the period 1991 to 2001. The model performed well in the verification period with a Nash-Sutcliffe correlation $R^{2}=0.96$. There was a good agreement between the observed and estimated outflows in the verification period as shown in observed flows at Mangochi station as shown in Fig. (5). The 1991 to 2001 was a low level/outflow period of the lake and the model even performed well during this period. Lake outflows simulated by equation 5 have shown to match measured flows. Some examples of the approach in literature are: simulation of Lake Tana outflows [14] and Lake Ziway [16] outflows in Ethiopia.

\subsection{Direct Rainfall $P_{L}$ and Evaporation $\operatorname{Evap}_{L}$ Over Lake Malawi}

Precipitation and evaporation over the lake has been estimated from climate stations along the lake for the period 1971 to 1990 (Fig. 1). Several studies have shown that evaporation from an open water body is the largest component of the water balance but very difficult to accurately determine because of lack of climate stations within the lake area $[2,5,14]$. Evaporation estimates were based on a Penman method [17].

\section{LAKE WATER LEVEL SIMULATION}

The water balance model given in equation 2 is a differential equation with two unknowns at the same time. Solution to such types of equation involves simulating the water level on monthly basis or longer time steps $[5,14]$. The differential equation 2 can be written as equation 6 with an integration period of $\Delta t$ (one month and above)

$\Delta L=R_{L}(t)-\operatorname{Evap}_{L}(t)+Q_{\text {bala }}+\varepsilon(t)$

Depending on available data, the above model can further be simplified by neglecting some of the terms on the right hand side. In our case we have assumed zero net groundwater flux because of lack of data on net ground flow around the lake. Due to lack of information on surface area - lake depth relationship, a constant surface area has been assumed in equation 6. However, the direct net evaporation (i.e. evaporation less rainfall) fluxes on the lake surface are also affected by climate change and, depending on the magnitude of the change, could have significant effects on the assessed impacts [18]. In this study, a constant surface area was based on recommendations from previous studies [5, 19]. The $b$ value in equation 5 indicates that change in lake levels has minor effect on the lake surface area. This simplifies equation 6 into the following form:

$\Delta L=R_{L}(t)-\operatorname{Evap}_{L}(t)+\left(\frac{Q_{\text {in }}(t)-Q_{\text {out }}(t)}{A_{L}}\right)+\varepsilon(t)$

\subsection{Model Calibration and Verification}

The water balance model (WBM) presented in equation 7 was calibrated and verified using available mean monthly 


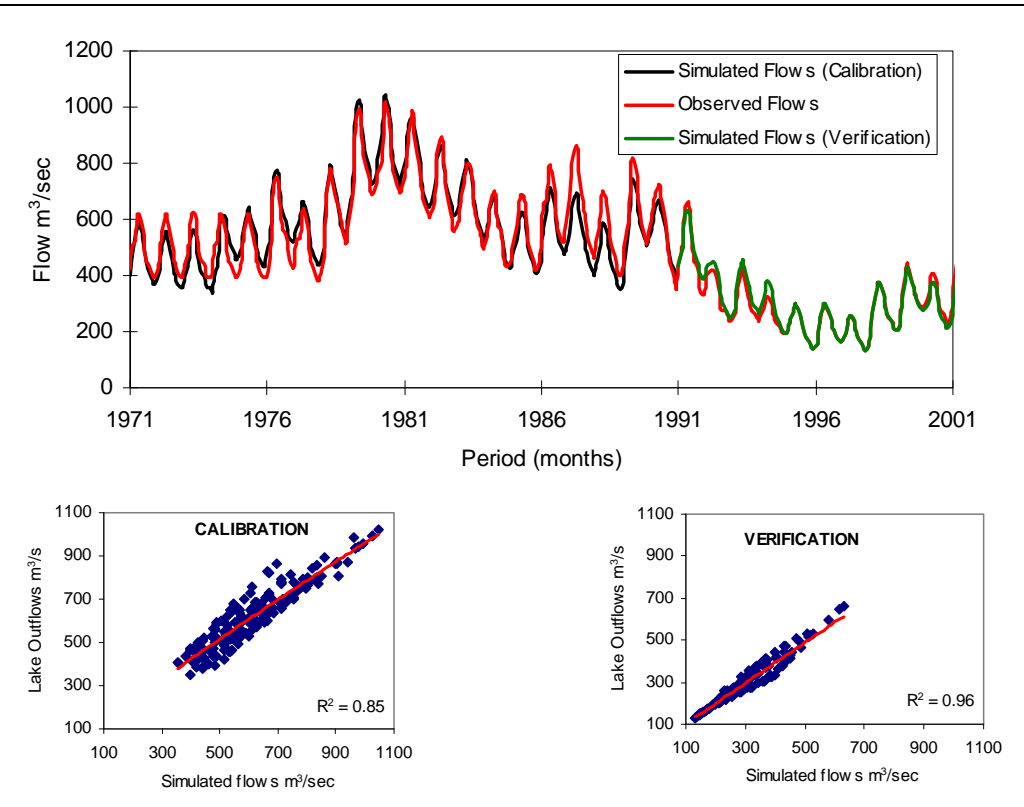

Fig. (5). Simulated flows of Mangochi outlet station by lake level-outlet flow equation.

data. The available data was split in two parts:- 1971 to 1985 as the calibration period and 1986 to 1990 as the verification period. Calibration and verification was based on the period 1971 to 1990 because this is the period with complete records in terms of all the WBM components. The approach in the calibration involved solving equation 7 to estimate the lake level based on previous time step outflow and assuming the initial starting lake level is the observed lake level of the first data point in the lake level data series. Time lag has also to be considered between the inflow and outflow, which is difficult to estimate. The approach adopted in this research was by trial and error. This involved changing the time lag between the inflow and outflow and then observing the model fit with the observed levels. Equation 7 was tabulated in EXCEL and iteratively adjusting the time lag between the input and output in equation 7. The final selection of the best estimates was based on Nash $R^{2}$ criteria [20] and simulated levels have been compared with observed levels. For lakes and linear reservoirs equation 5 may be used as check for estimates by equation 7. Similar approach has been employed in simulating water levels of Lake Ziway and Lake Tana in Ethiopia [14, 16].

The water balance model was simulated using two different approaches. The first approach was simulation "with updating' and the second approach was simulation 'without updating' normally known as 'simulation mode' in the scientific literature.

\subsubsection{Model Simulation 'with Updating'}

Model simulations 'with updating' involves using previously observed values of the output in the model in order to issue a forecast. Models run in updating mode normally can issue a reliable estimate at one time step ahead of the current time step [21]. Beyond that the forecast is not all that reliable and depends on the persistence of model errors. This may be particularly difficult to see unless analysis of the residual errors is done. The water balance model was run in 'updating' mode using the previously observed levels as input function in the model in order to issue a forecast as described in equation 8 and 9. The error term was ignored in the 'updating' mode.

$$
\Delta L(t)=R_{L}(t)-\operatorname{Evap}_{L}(t)+\left(\frac{Q_{\text {in }}(t)-Q_{\text {out }}(t)}{A_{L}}\right)
$$

$L_{E s t}(t)=L_{O b s}(t-1)+\Delta L(t)$

$L_{E s t}$ and $L_{O b s}$ in equation 9 stands for estimated and observed lake level respectively, average from the three water level stations. The results of the simulation have been presented in Fig. (6). The results show a good correlation between observed and estimated levels with a NashSutcliffe correlation $R^{2}=0.98$. The consistent lag between observed and modelled levels in Fig. (6) could be attributed to model errors and data errors. Models run in 'updating' mode normally perform very well but lacks the capability of issuing a long term forecast as required in the case of Lake Malawi. Model run in simulation mode would be useful in the operation of Liwonde barrage in regulating flows from the lake on monthly basis only.

\subsubsection{Model Calibration and Verification, Simulation 'without Updating'}

Observing errors and error trends in model predictions helps to improve the model structure and prediction so that the improved model can be run in simulation mode. The ultimate performance of a model depends on the model to give good estimates in simulation mode [21]. Simulation mode involves using previously estimated values as the input function in the model in order to issue a forecast. The model relies much on its previously predicted values to estimate future trend. This requires analysis of error trends so that the error term should be incorporated with better accuracy in the model. In this research the model was run in 'simulation mode' with the initial starting water level as the observed water level of the first data point. The rest of the levels were estimated based on previous model output. 

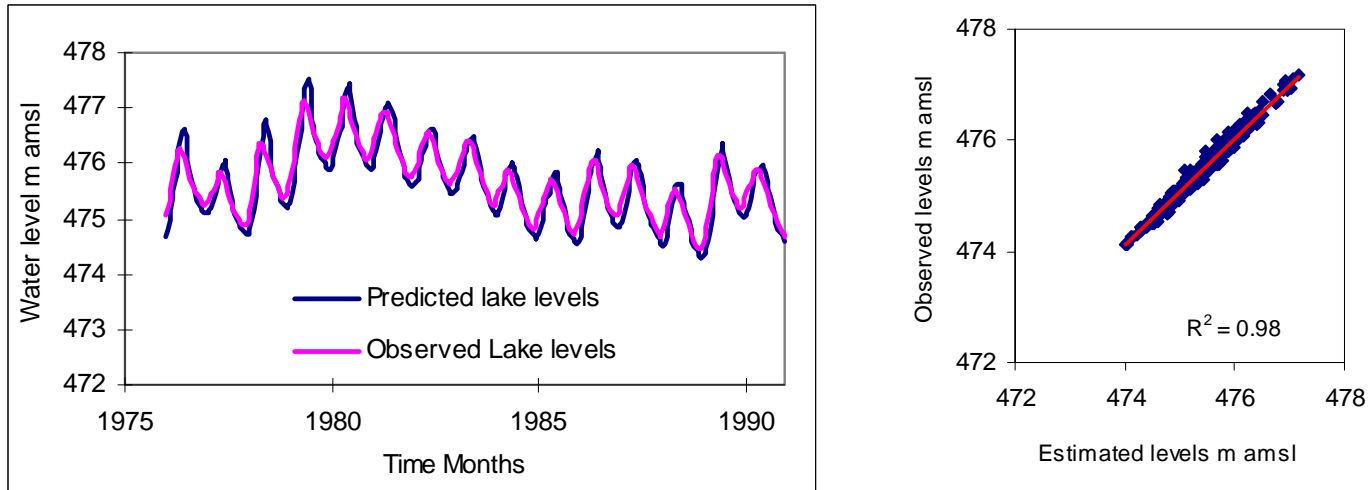

Fig. (6). Comparison between simulated and estimated flows based on water balance model run in 'updating' mode.

Analysis of the errors between the observed and simulated level was done before updating the model. The error term was observed to increase linearly with time from the point when the first forecast was issued. Fig. (7) is the relationship between the error and time. The time $t$ starts from the point where model simulation started and in steps equivalent to model simulation time up to the last data point $N$. The observed increase in the error overtime as shown in Fig. (7) shows that the same error keeps on recurring at every time step of the simulation. This results in accumulation of model error and hence the divergence between the observed and predicted values. The error could be attributed to the inclusion of groundwater flux in the model residues, errors in the input data records and the assumption behind the other water balance components.

From the results of error analysis, a linear relationship was observed between model errors and time step $t$ with an $R^{2}=0.99$ as presented in Fig. (7). The error term presented in equation 10 was deduced from the plot and incorporated in the water balance model (equation 7) in order to issue a forecast in simulation mode. Finally the water level was simulated based on equation 11. Results of running WBM in simulation mode have been presented in Fig. (8).

$\varepsilon_{t}=0.0554 t$

$L_{E s t}(t)=L_{E s t}(t-1)+\Delta L(t)$

The WBM produced a good simulation of the levels of Lake Malawi in the calibration period. Generally there is a good agreement between the observed and estimated levels

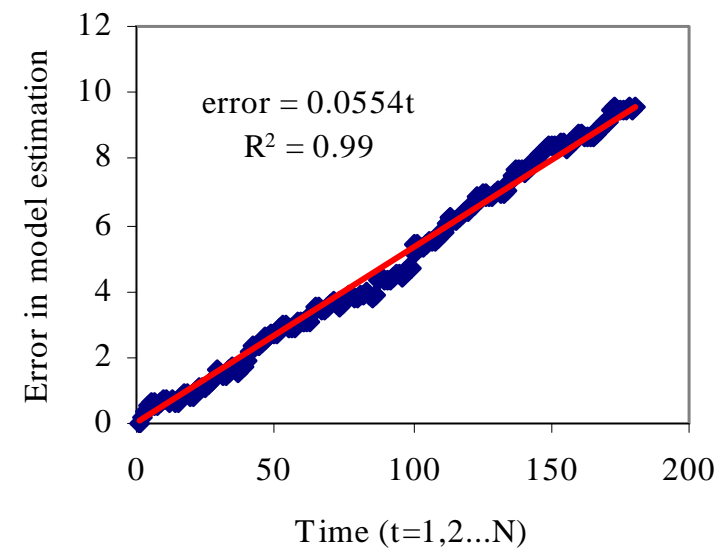

Fig. (7). Trend of model errors based on water balance model run in 'without updating' mode before error correction. as shown in Fig. (8) $\left(R^{2}=0.88\right)$. The disagreement in the observed and estimated levels in the year 1977 and 1978, then in the dry season of 1984 and 1985 could be attributed to errors in the model input variables such as rainfall, evaporation, measured lake level and outflow. The other contributing factor could be the incorporation of net groundwater flux in the model residuals.

\section{LAKE LEVEL AND OUTFLOW SENSITIVITY TO CLIMATE CHANGE}

Analysis of the WBM components has revealed that rainfall and evaporation are the major components of the WBM. Any change in these two major components could have an adverse impact on the water level of Lake Malawi. Among the water balance components rainfall is the component which varies most while evaporation varies least. It is therefore necessary to analyse lake level and outflow sensitivity to climate change based on projected changes in the water balance model components.

\subsection{Climate Change Data}

General circulation models (GCMs) for simulating future climate data for temperature and rainfall were obtained from the United Kingdom (UK) Meteorological Office Hadley Centre [22]. The Hadley Centre is responsible for climate change prediction work and they distribute data through IPCC Data Distribution Centre (IPCC-DDC). IPCC-DDC is designed primarily for climate change researchers and provides climate, socio-economic and environmental data, both from the past and also in scenarios projected into the future [23].

Research at the Hadley Centre involves validation of GCMs based on baseline data from 1961 - 1990. GCM data from Hadley Centre are derived from UK Meteorological Office coupled ocean-atmosphere GCM (HadCM3) experiments and normalized over the period $1961-1990$ [23]. The period 1961 - 1990 is the standard baseline period set by IPCC based on World Meteorological Organization (WMO) normal period. GCMs are derived based on emission scenarios which were developed by IPCC in 2000. Emission scenarios are alternative images regarding how the future will be in terms of greenhouse gas emission. IPCC emission scenarios are organized into four main families (A1, B1, A2, and $\mathrm{B} 2$ ).

GCM outputs from the UK HadCM3 experiments derived based on different emission scenarios have a resolution of $2.5^{\mathrm{O}}$ latitude $\times 3.5^{\mathrm{O}}$ longitude. The coarse resolution of the 

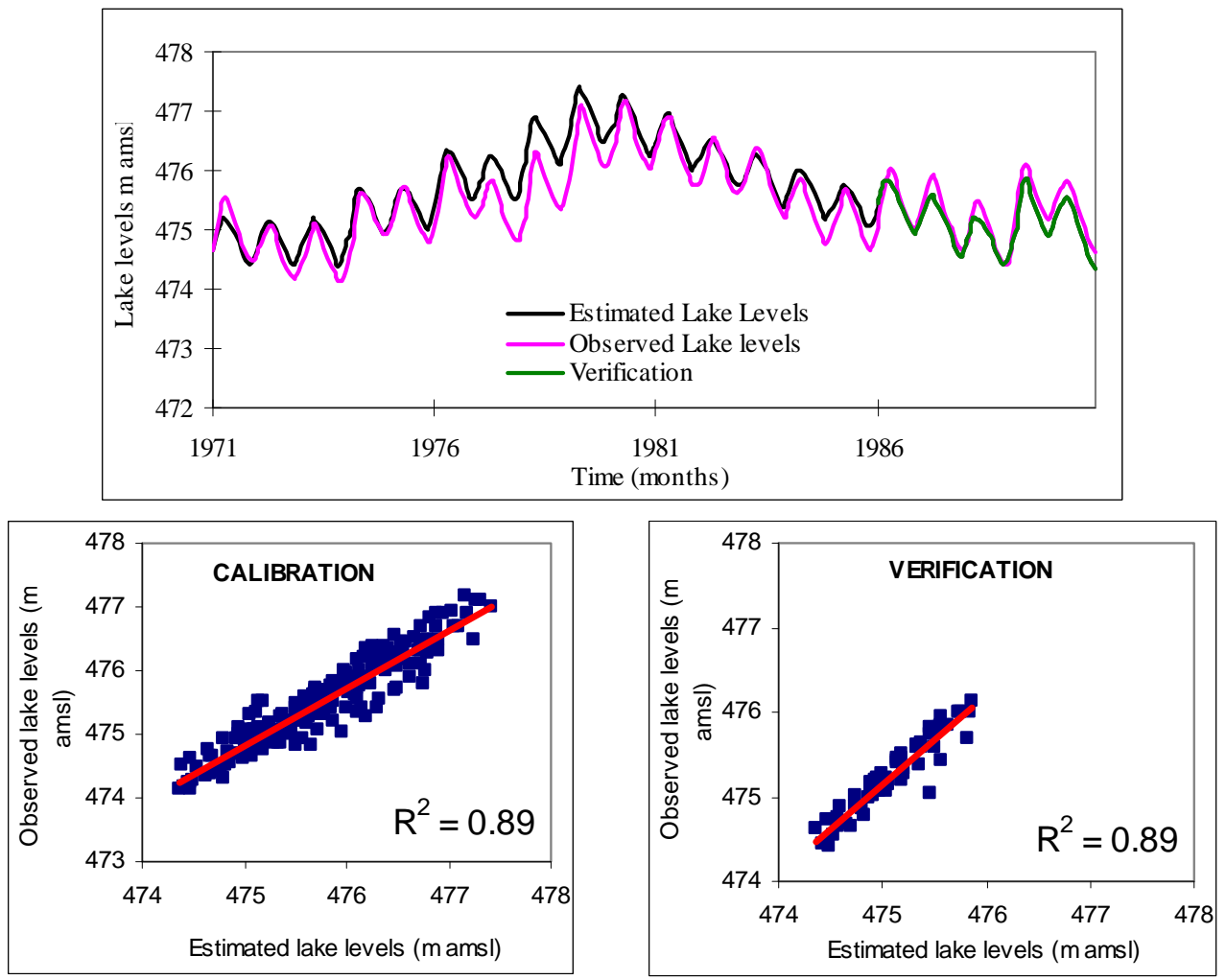

Fig. (8). Comparison between simulated and estimated flows based on water balance model run in 'simulation' mode.

GCM makes it difficult to take into account features on the landscape such as hills and lakes which can influence the local climate [24]. Downscaling is also required in catchment areas where climate variability is likely to be high such as Lake Malawi catchment area. In view of this climate researchers have developed tools for downscaling GCM outputs to the required area utilizing either dynamical or statistical methods. This study has utilized the downscaled results obtained by using the Statistical Downscaling Model (SDSM) which was downloaded from the SDSM UK web site (www.sdsm.org.uk) [24]. SDSM model is a hybrid of stochastic weather generators and regression based techniques used to linearly correlate large scale GCM parameters to local scale weather generator parameters such as rainfall occurrence and intensity. This is based on the fundamental assumption that regional climate is conditioned by local physio-graphic characteristics as well as the larger atmospheric state. Predictor variables (Table 2) used in the study were selected from HadCM3 data base based on recommendations by Wilby and Dawson (2007) that "the predictor variables should be both physically and conceptually sensible in terms of the known meteorological variables such as rainfall or temperature and should correlate with the predictand such as rainfall or temperature".

Future projected climate of the lake (rainfall and temperature) based on HadCM3 emission scenarios were used for simulating the future behaviour of water levels of Lake Malawi.

\subsection{Lumped Conceptual Hydrological Model}

The most difficult component to estimate among the water balance components is the runoff from the land catchment as the runoff originates from river basins with different catchment characteristics. In view of this a lumped conceptual hydrological model, NAM [25], was used to convert catchment rainfall into runoff. The model was calibrated and fitted to convert monthly rainfall over the lake catchment (Tanzania, Malawi and Mozambique) into runoff. Runoff was calculated as a summation of runoff from of all the rivers draining into the lake. The results of the fitted model presented in Fig. (9) show a good agreement between estimated and observed runoff under both emission scenarios. The hydrological model overestimated some of the peak runoff and under estimated the minimum runoff for other years like 1979, 1980 and 1987, This could be attributed to errors in the input especially runoff from ungauged catchment which have been estimated by extrapolation based on rainfall coverage. Rainfall could also contribute to the residual errors due to an

Table 2. List of Selected Predictor Variables from HadCM3 Data Base

\begin{tabular}{|c|c|c|c|c|}
\hline Item & Daily variable & Code & Rainfall & Temperature \\
\hline & & & \multicolumn{2}{|c|}{ Selected predictor } \\
\hline 1 & Mean temperature temp & temp & & $\mathrm{x}$ \\
\hline 2 & $\begin{array}{c}\text { Near surface relative } \\
\text { humidity }\end{array}$ & rhum & $\mathrm{x}$ & \\
\hline 3 & $\begin{array}{c}\text { Relative humidity at } 500 \\
\text { hPa height }\end{array}$ & r500 & & \\
\hline 4 & $\begin{array}{c}\text { Near surface specific } \\
\text { humidity }\end{array}$ & shum & $\mathrm{x}$ & $\mathrm{x}$ \\
\hline 5 & $\begin{array}{l}\text { Meridional velocity } \\
\text { component }\end{array}$ & $* *$ _v & $\mathrm{x}$ & \\
\hline
\end{tabular}



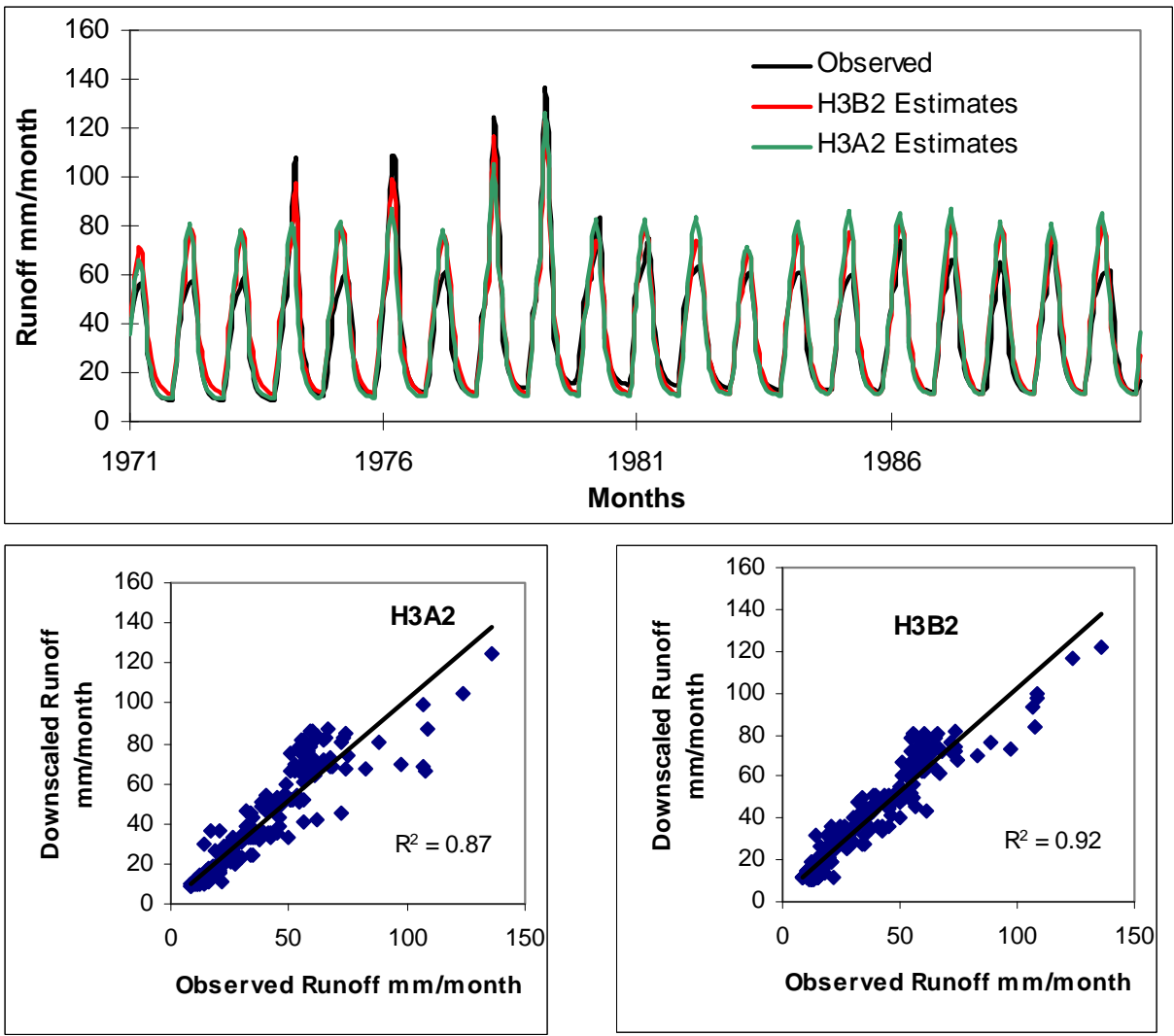

Fig. (9). Results of fitting NAM model over Lake Malawi land catchment.

even distribution of rainfall station within the catchment area.

\subsection{Applying Climate Change to the WBM}

Climate data used in the study have been obtained from the HadCM3 GCM emission scenarios of the UK Hadley Centre for climate change. The GCMs were used to define a baseline climate of the lake based on observed climate data for the period $1971-1990$. This period is within the IPCC base period of 1961 - 1990. The projected future climate data based on IPCC emission scenarios; B2 and A2 have been used to estimate the future behaviour of the lake.

Downscaled daily temperature from HadCM3 GCMs has been used to estimate future evaporation from the lake and the land catchment area of the lake. Runoff from the lake catchment has been estimated using calibrated rainfall runoff model, NAM [25]. Results of the downscaled rainfall, tem-

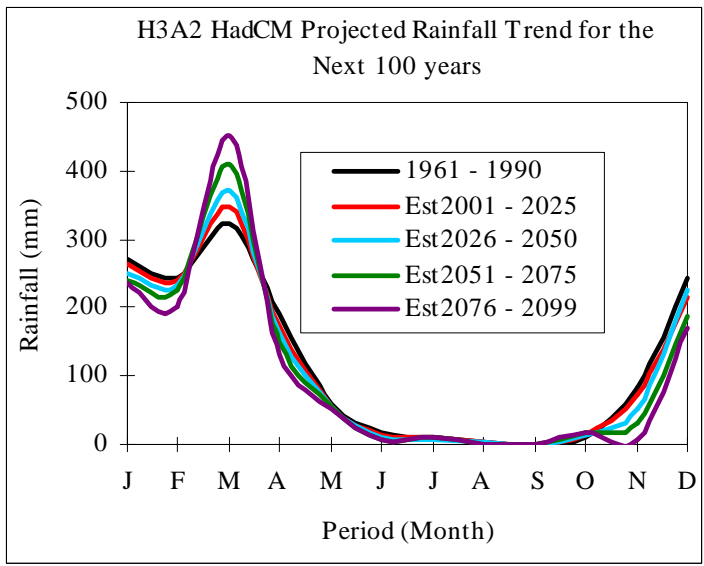

perature and evaporation using Statistical Downscaling Method (SDSM) [24] have been presented in Fig. (10), Fig. (11 and Fig. 12) respectively. The results show that there is a marked change in the magnitude and seasonal rainfall pattern. The rainfall pattern shows an increase in rainfall during the months of March and a decrease in rainfall during the month of January and February (Short rainfall season with high rainfall within a short period and longer dry season). The observed pattern is similar in both $\mathrm{A}$ and $\mathrm{B}$ emission scenarios. High intense rainfall within a short period will lead to flooding along the lakeshore. This normally results in full opening of the Liwonde barrage which controls outflows from the lake. Full opening of the barrage ends up in transferring the problem down to the Lower Shire Valley. Release of water from the lake to avoid flooding within a short period compounded with long dry season will result in low lake levels.

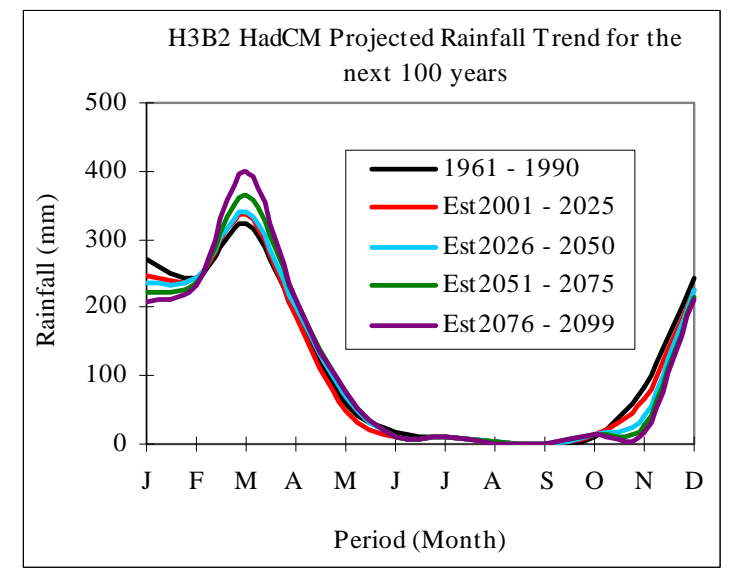

Fig. (10). Projected rainfall pattern over Lake Malawi based on HadCM3 emission scenario. 

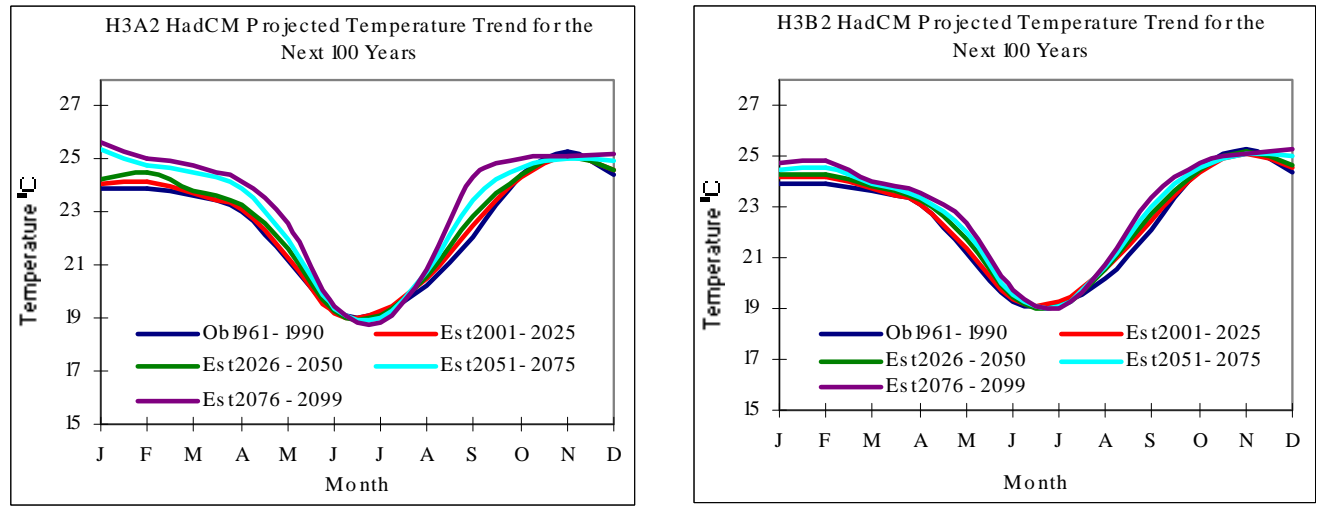

Fig. (11). Projected temperature pattern over Lake Malawi based on HadCM3 emission scenario.
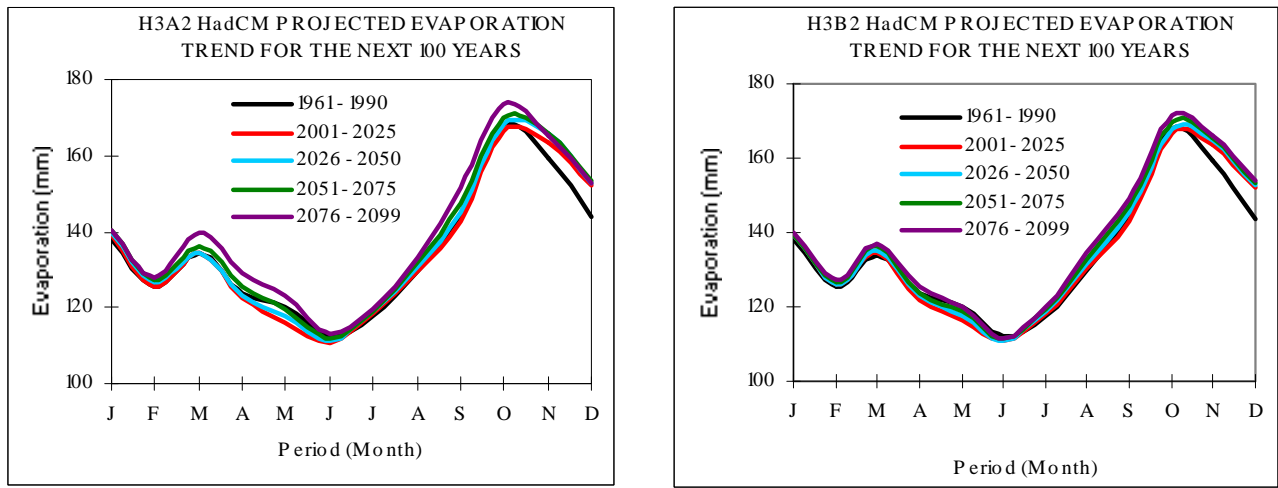

Fig. (12). Projected evaporation pattern over Lake Malawi based on HadCM3 emission scenario.

In the case of temperature the results shows that predicted temperature will increase over the lake and the land catchment during the months of January - May, August, September, October and December. The months of June, July and November have no marked change in temperature. Temperature increase will result in increase in evaporation as shown in Fig. (11) and Fig. (12). The major challenge will be on the land catchment where an increase in evaporation will lead to an increase in crop water requirement (water required for full growth of crops and natural vegetation). This will result in reduced runoff into the lake as well. Increase in evaporation over the lake, reduction in runoff and longer dry season will reduced the net basin supply component of the lake in water balance model. Estimated future temperature based on both emission scenarios was later on used as input data in Hargreaves evaporation model to estimate future evaporation over the lake. The Hargreaves equation [26] is as follows:

$$
E T_{0}=\alpha *\left(T_{\text {mean }}+17.8\right) *\left(T_{\max }-T_{\text {min }}\right)^{0.5 * R a}
$$

where $\mathrm{ET}_{\mathrm{o}}$ is in $\mathrm{mm}$ per day, $\alpha$ is coefficient of the Hargreaves equation, $T_{\text {mean }}, T_{\max }$ and $T_{\min }$ are the mean, maximum and minimum temperature in ${ }^{0} \mathrm{C}$ respectively and $R_{a}$ is extraterrestrial solar radiation $M J m^{2} d^{1}$.

The results shows a slight decrease in evaporation for the months of March, April, and May for the period $2001-2050$ and an increase in evaporation during the months of October, November and December under both scenarios. The period 2051 - 2075 has an evaporation trend similar to the base period of 1961 - 1990 with an increase during the months of October, November and December. Marked increase in evaporation has been observed under both emission scenarios for the period $2076-2099$. A2 emission scenarios estimates are higher than the estimates made using B2 emission scenarios.

The projected increase in evaporation especially during the months of July through December as depicted by both emission scenarios for the period 2051 - 2099 coupled with the change in rainfall pattern will have an effect on the water balance of Lake Malawi. It is therefore necessary to use projected estimates in the water balance model to estimate the future behaviour of lake levels. The estimated changes in rainfall, runoff and evaporation derived from HadCM3 for the period 2001-2100 in 25 years mean scenarios were applied to the Lake Malawi WBM. Outflow from the lake was estimated using the lake level-outlet flow equation (equation 5) calibrated in section 3.2. Lake level simulation was done using the calibrated Water Balance Model with simulation without updating. The pattern of the future behaviour of the lake is now presented in Fig. (13). Under both emission scenarios the water level continues to drop from 2001 up to 2100. Mean monthly lake levels shown in Fig. (13) shows that during the first quarter of the century the water level ranges from 474.5 to $475.5 \mathrm{~m}$ amsl with a drop at the end of the first quarter then starts to gain till the mid of the second quarter of the century. From the mid of the second quarter of the century the water level ranges from 474.25 to 475.25 and till mid of the third quarter of the century. A marked drop was observed in the last quarter of the century where the water level range ranges from 473.75 to 474.75 . The lowest lake level has been predicted at mid of the last quarter of the century by both emission scenarios. A total fall in water level of the order 0.5 to $1.0 \mathrm{~m}$ is forecast for this century based on climate change. 


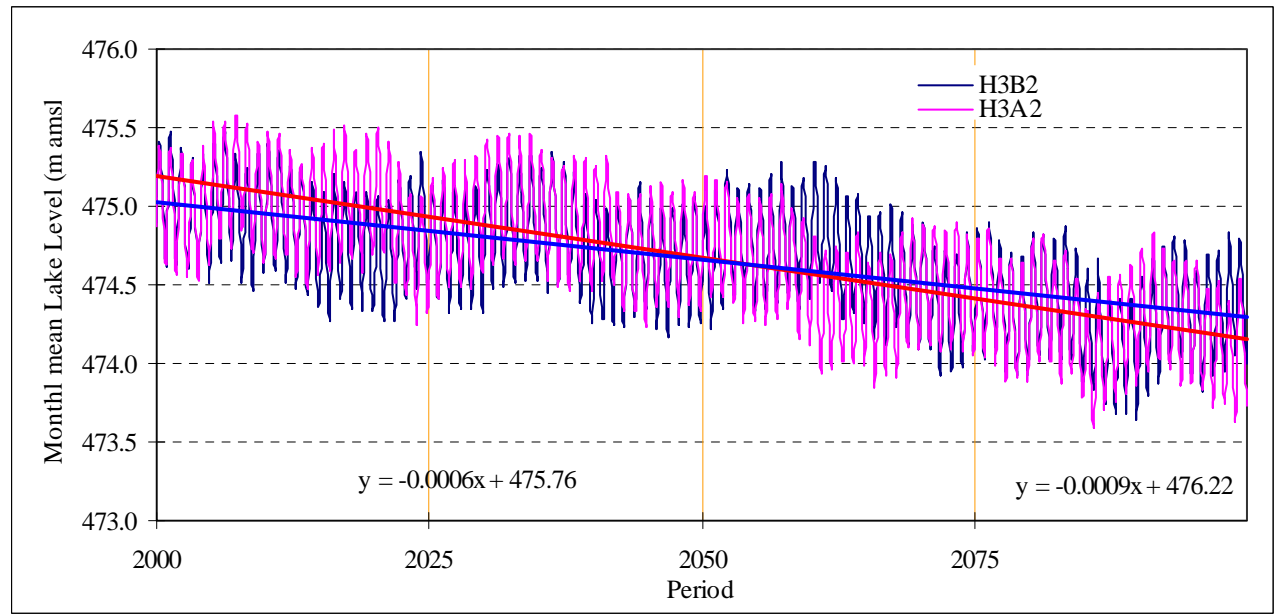

Fig. (13). Projected future behaviour of the lake based on HadCM3 A2 and B2 Scenarios.

The expected low lake levels as projected by the emissions scenarios will have far reaching consequences especially on the downstream benefits along the Shire river. According to Calder et al. (1995) there is no outflow from the lake with an observed water level below $470.1 \mathrm{~m}$ amsl as was the case from 1915 to 1935 . Table $\mathbf{3}$ is a summary of the mean predicted water level for every 25 years. The predicted continuous decrease in lake levels as predicted by the two scenarios indicates that there is going to be a drop in the water levels of the lake even if the magnitude will not be as predicted. This calls for sustainable management of the lake catchment as well as other hydropower generation option along the Shire river and the rivers in the Lake Malawi catchment area.

The difference in the projected annual mean lake level by the two emission scenarios indicates the limitation of climate change scenarios for climate change impacts. There are different emission scenarios from different experiments and the HadCM3 emission scenarios used in this research should serve as an example for modelling the hydrological response of large lake system to climate change. According to IPCC (2007) inter-model consistency in regional precipitation and temperature change are high over South East Africa, including Lake Malawi. There is no clear direction and magnitude in the change of temperature and rainfall within the South East African region with each GCM model giving its own results and direction [27]. The results presented here should therefore not serve as the actual predicted future lake levels of Lake Malawi but more as an illustration of the sensitivity of water levels of Lake Malawi to one possible future possible climate change pattern under HadCM3 A2 and B2 emission scenarios. The other scenarios and GCM will also result in a different water level trend.
Despite climate change Lake Malawi is also under threat due to population increase in Malawi. Malawi current population is 13 million and is expected to increase to 20 to 30 million during this century. This will result in increase in demand for water for domestic use, irrigation and hydropower generation.

\section{SUMMARY AND CONCLUSIONS}

In this paper previous water balance studies on the WBM of Lake Malawi have been reviewed. In all the previous studies estimates of the behaviour of the lake was based on the probability analysis and outflows from the lake were based on flow rates at Liwonde barrage which is $80 \mathrm{~km}$ downstream of the main lake outlet station of Mangochi. In this study Lake outflows in the WBM were based on the main lake outlet gauging station at Mangochi. Rainfall and evaporation over the lake was estimated from climate stations along the lakeshore. This could be a contributing factor to model errors since the lake area of $28750 \mathrm{~km}^{2}$ covers a significant portion of the whole catchment of $124,500 \mathrm{~km}^{2}$. The other contributing factor could be lack of data on groundwater flux.

The results of sensitivity analysis of the WBM of Lake Malawi to climate change have shown that water level will continue to drop following a decrease in the rainfall season and an increase in evaporation rates from the lake. The results further shows that it is very unlikely for the water level to increase to a maximum height of $477 \mathrm{~m}$ amsl as was in 1980. Future assessed lake levels based in HadCM3 A2 and B2 emission scenarios shows a tendency to fall approaching an average of $475 \mathrm{~m}$ amsl for the first half of the century and $474 \mathrm{~m}$ amsl for the last half of the century. Similar analysis by Neuland (1984) based on probability analysis showed that

Table 3. Summary of Projected Lake Levels under HadCM3 Emission Scenarios

\begin{tabular}{|c|c|c|c|c|}
\hline Period & $\mathbf{2 0 0 1} \mathbf{- 2 0 2 5}$ & $\mathbf{2 0 2 6} \mathbf{- 2 0 5 0}$ & $\mathbf{2 0 5 1} \mathbf{- 2 0 7 5}$ & $\mathbf{2 0 7 6}-\mathbf{2 1 0 0}$ \\
\hline Emission Scenario & & \multicolumn{3}{|c|}{ Projected mean level for every 25 years (m amsl) } \\
\hline \hline H3A2 & 474.99 & 474.82 & 474.74 & 474.40 \\
\hline H3B2 & 474.88 & 474.78 & 474.67 & 474.36 \\
\hline
\end{tabular}


there is little risk of the future lake level exceeding $477.8 \mathrm{~m}$ and Neuland's future assessment of lake levels showed a tendency to fall approaching gradually an equilibrium of 475 $\mathrm{m}$ amsl. A marked drop in water level is predicted in the last quarter of the century by both scenarios. The predicted future drop in water level of the lake calls for alternative proposals for both hydropower and irrigation development as the current system relies too much on the lake.

The water level and outflows from Lake Malawi have been modelled using a WBM. The WBM run in simulation mode has shown to be a reliable hydrological tool for water resources management and decision making for Lake Malawi-Shire river system especially in application such as $\mathrm{Li}$ wonde barrage flow regulation, issuing flood and low lake level warning. This could help all the interested parties in the system in taking necessary steps in the operation of the water resources project within the system in a sustainable manner. Ultimate sustainable management of Lake Malawi depends on the sustainable operation and management of the water resources projects along the Shire river which derives its benefits from the water storage of Lake Malawi. This will require reducing pressure on the water resources development along the Shire river by a balanced water resources development set up to be spread throughout the country to avoid overdependence on the Shire river as it is the case now.

For the ultimate performance of the model it is recommended that the model should be updated on regular basis based on the current observed data due to uncertainties in GCM emission scenarios in predicting future climate [9]. The GCM used in the study should serve as an example of one possible future climate pattern of the lake.

\section{REFERENCES}

[1] Shahin M. Hydrology and water resources of Africa. Kluwer Academic Publishers: London 2002.

[2] Neuland H. Abnormal high water levels of Lake Malawi? - An attempt to assess the future behaviour of the lake water levels. Geo J 1984; 9: 323-34.

[3] Kumambala PG, Ervine A. Site selection for combine hydro, irrigation and water supply in Malawi: Assessment of water resource availability. Desalination 2008; 252: 120-8.

[4] Kidd CHR. A water resources evaluation of Lake Malawi and the Shire river. World Meteological Organization: Geneva 1983.

[5] Calder IR, Hall RL, Bastable HG, et al. The impact of land use change on water resources in sub-Saharan Africa: a modelling study of Lake Malawi. J Hydrol 1995; 170: 123-35.

[6] Munthali SM. Protected areas and people: sustaining lake malawi's ecology. Department of National Parks and Wildlife, Malawi: Lilongwe 1994.
[7] Konings AD. Lake Malawi cichlids. A review of the sand-dwelling species of the genus Aulonocara, with the description of three new species. In: Konings AD, Ed. The Cichlids Yearbook Cichlid Press 1995; pp. 25-6.

[8] SADC. Southern African Development Community; 2009 [updated 2009; cited $2009 \quad 15$ May]; Available from: http://www.sadc.int/floods/Malawi.php

[9] IPCC. Climate Change 2007: Synthesis Report. Intergovernmental Panel on Climate Change: Valencia, Spain 2007.

[10] Clay E, Bohn L, Armas EBd, Kabambe S, Tchale H. Malawi and Southern Africa Climatic Variability and Economic Performance. World Bank: Washington DC 2003.

[11] Jury MR, Gwazantini ME. Climate variability in Malawi, part 2: sensitivity and prediction of lake levels. Int J Clim 2002; 22: 130312.

[12] Healy RW, Winter TC, LaBaugh JW, Franke OL. Water Budgets: Foundations for Effective Water-Resources and Environmental Management. US Geological Survey: Virginia, USA 2007.

[13] Drayton RS. Variations in the level of Lake Malawi. Hydrol Sci 1984; 29: 1-10.

[14] Kebede S, Travia Y, Alemayehu T, Marc V. Water balance of Lake Tana and its sensitivity to fluctuations in rainfall, Blue Nile basin, Ethiopia. J Hydrol 2006; 316: 233-47.

[15] Sene KJ. Effect of variations net basin supply on lake levels and outflows. Hydrol Proc 1998; 12: 559-73.

[16] Vallet-Coulomb C, Legessea D, Gassea F, Travic Y, Chernetd T. Lake evaporation estimates in tropical Africa (Lake Ziway, Ethiopia). J Hydrol 2001; 245: 1-18.

[17] Allen RG, Pereira LS, Raes D, Smith M. Crop evapotranspiration Guidelines for computing crop water requirements - FAO Irrigation and drainage paper 56. Food and Agriculture Organization of the United Nations (FAO): Rome 1998.

[18] Adeloye AJ, Nawaz NR, Montaseri M. Climate change water resources planning impacts incorporating reservoir surface net evaporation fluxes: A Case Study. Int J Water Res Dev 1999; 15: 561-81.

[19] Kingdon MJ, Bootsma HA, Mwita J, Mwichande B. River Discharge and Water Quality. In: Bootsma HA, Hecky RE, Eds. Water Quality Report, Lake Malawi/Nyasa Biodiversity Conservation Project, Salima, Malawi 1999; pp. 31-69.

[20] Nash JE, Sutcliffe JV. River flow forecasting through conceptual models. Part I-a discussion of principles. J Hydro 1970; 10: 28290 .

[21] Kachroo RK. River flow forecasting. Part 1. A discussion of the principles. J Hydro 1992; 133: 1 -15.

[22] IPCC-DDC. Intergovernmental Panel on Climate Change (IPCC), IPCC Data Distribution Centre. 2008 [updated 2008; cited 2008 February 28]; Available from: http://www.ipcc-data.org/

[23] IPCC. Special Report on Emmission Scenarios. Intergovernmental Panel on Climate Change: Cambrige, UK 2000.

[24] Wilby RL, Dawson CW. SDSM 4.2 A decision support tool for the assessment of regional climate change impacts. Lancaster University, UK 2007.

[25] DHI. A Modelling System for Rivers and Channels. Reference Manual. Danish Hydraulic Institute: Denmark 2008.

[26] Hargreaves GH, Samani ZA. Estimating potential evaptranspiration. J Irri Dra Div - ASCE 1982; 108: 225-30.

[27] IPCC. Climate Change 2001: The Scientific Basis. Cambridge University Press: Cambridge, United Kingdom 2001.

Received: December 22, 2009

(C) Kumambala and Ervine; Licensee Bentham Open.

This is an open access article licensed under the terms of the Creative Commons Attribution Non-Commercial License (http://creativecommons.org/licenses/by-nc/3.0/) which permits unrestricted, non-commercial use, distribution and reproduction in any medium, provided the work is properly cited. 